\title{
Leptospirosis, Climate and Satellite-based Environmental Factors: A Temporal Modeling
}

\section{Pandji W. Dhewantara, Wenbiao Hu, Wenyi Zhang, Wenwu Yin, Fan Ding, Abdullah Mamun, Ricardo J. Soares Magalhaes}

University of Queensland, Australia

\section{Objective}

To quantify the effects of climate variability, selected remotely-sensed environmental factors on human leptospirosis in the highrisk counties in China.

Introduction

Leptospirosis is a zoonotic disease caused by the pathogenic Leptospira bacteria and is ubiquitously distributed in tropical and subtropical regions. Leptospirosis transmission driven by complex factors include climatic, environmental and local social conditions [1]. Each year, there are about 1 million cases of human leptospirosis reported globally and it causes approximately 60,000 people lost their lives due to infection [2]. Yunnan Province and Sichuan Province are two of highly endemic areas in the southwest China that had contributed for $47 \%$ of the total national reported cases during 2005-2015 [3]. Factors underlying local leptospirosis transmission in these two areas is far from clear and thus hinder the efficacy of control strategies. Hence, it is essential to assess and identify local key drivers associated with persistent leptospirosis transmission in that areas to lay foundation for the development of early-warning systems. Currently, remote sensing technology provides broad range of physical environment data at various spatial and temporal scales [4], which can be used to understand the leptospirosis epidemiology. Utilizing satellite-based environmental data combined with locally-acquired weather data may potentially enhance existing surveillance programs in China so that the burden of leptospirosis could be reduced.

\section{Methods}

This study was carried out in two counties situated in different climatic zone in the southwestern China, Mengla and Yilong County (Fig 1). Total of 543 confirmed leptospirosis cases reported during 2006-2016 from both counties were used in this analysis. Time series decomposition was used to explore the long-term seasonality of leptospirosis incidence in two counties during the period studied. Monthly remotely-sensed environmental data such as normalized difference vegetation index (NDVI), modified normalized water difference index (MNDWI) and land surface temperature (LST) were collected from satellite databases. Climate data include monthly precipitation and relative humidity (RH) data were obtained from local weather stations. Lagged effects of rainfall, humidity, normalized difference vegetation index (NDVI), modified normalized difference water index (MNDWI) and land surface temperature (LST) on leptospirosis was examined. Generalized linear model with negative binomial link was used to assess the relationships of climatic and physical environment factors with leptospirosis. Best-fitted model was determined based on the lowest information criterion and deviance.

\section{Results}

Leptospirosis incidence in both counties showed strong and unique annual seasonality. Bi-modal temporal pattern was exhibited in Mengla County while single epidemic curve was persistently demonstrated in Yilong County (Fig 2). Total of 10 and 20 models were generated for Mengla and Yilong County, respectively. After adjusting for seasonality, final best-fitted models indicated that rainfall at lag of 6-month (incidence rate ratio $($ IRR $)=0.989 ; 95 \%$ confidence interval $(\mathrm{CI}) 0.985-0.993, \mathrm{p}<0.001$ ) and current LST (IRR=0.857, 95\% CI:0.729-0.929, $\mathrm{p}<0.001)$ significantly associated with leptospirosis in Mengla County (Table 1). While in Yilong, rainfall at 1-month lag, MNDWI (5-months lag) and LST (3-months lag) were associated with an increased incidence of leptospirosis with a risk ratio of 1.013 (95\%CI: 1.003-1.023), 7.960 (95\%CI: 1.241-47.66) and 1.193 (95\% CI:1.095$1.301)$, respectively. 


\section{Conclusions}

Our study identified lagged effect and relationships of weather and remotely-sensed environmental factors with leptospirosis in two endemic counties in China. Rainfall in combination with satellite derived physical environment factors such as flood/water indicator (MNDWI) and temperature (LST) could help explain the local epidemiology as well as good predictors for leptospirosis outbreak in both counties. This would also be an avenue for the development of leptospirosis early warning system in to support leptospirosis control in China.

\section{References}

1. Haake DA, Levett PN. 2015. Leptospirosis in humans. Curr Top Microbiol Immunol. 387, 65-97. PubMed https://doi.org/10.1007/978-3-662-45059-8_5

2. Costa F, et al. 2015. Global Morbidity and Mortality of Leptospirosis: A Systematic Review. PLoS Negl Trop Dis. 9, e0003898. PubMed https://doi.org/10.1371/journal.pntd.0003898

3. Dhewantara PW, et al. 2018. Epidemiological shift and geographical heterogeneity in the burden of leptospirosis in China. Infect Dis Poverty. 7, 57. PubMed https://doi.org/10.1186/s40249-018-0435-2

4. Herbreteau V, Salem G, Souris M, Hugot JP, Gonzalez JP. 2007. Thirty years of use and improvement of remote sensing, applied to epidemiology: from early promises to lasting frustration. Health Place. 13, 400-03. PubMed https://doi.org/10.1016/j.healthplace.2006.03.003

Table 1. Parameter estimates of the best-fitted model of the association of climatic and remotely-sensed variables with leptospirosis incidence in Mengla County and Yilong County, China

\begin{tabular}{|c|c|c|c|c|}
\hline Study site & Predictor & Lag (month) & IRR $(95 \%$ CI) & P-value \\
\hline \multirow{3}{*}{ Mengla County } & SAF & 0 & $3.388(2.400-4.783)$ & $<0.001$ \\
\cline { 2 - 5 } & Rainfall & 6 & $0.989(0.985-0.993)$ & $<0.001$ \\
\cline { 2 - 5 } & LST & 0 & $0.857(0.792-0.929)$ & $<0.001$ \\
\hline \multirow{4}{*}{ Yilong County } & SAF & 0 & $1.485(1.371-1.609)$ & $<0.001$ \\
\cline { 2 - 5 } & Rainfall & 1 & $1.013(1.003-1.023)$ & $<0.001$ \\
\cline { 2 - 5 } & MNDWI & 5 & $7.690(1.241-47.66)$ & $<0.001$ \\
\cline { 2 - 5 } & LST & 3 & $1.193(1.095-1.301)$ & $<0.001$ \\
\hline
\end{tabular}

Abbreviations: SAF, seasonal factor; MNDWI, modified normalized difference water index; LST, land surface temperature; $95 \% \mathrm{Cl}, 95 \%$ confidence interval

ISDS Annual Conference Proceedings 2019. This is an Open Access article distributed under the terms of the Creative Commons AttributionNoncommercial 4.0 Unported License (http://creativecommons.org/licenses/by-nc/3.0/), permitting all non-commercial use, distribution, and reproduction in any medium, provided the original work is properly cited. 